\title{
Trump's COVID-19 diagnosis and presidential illness
}

\author{
Rose McDermott, Brown University
}

AвSTRACT. President Donald Trump's COVID-19 illness, and the treatments he received, raise serious concerns about the adequacy of the Twenty-Fifth Amendment to handle cases of transient presidential incapacity. This is particularly challenging when the president refuses to acknowledge any impairment and resists any attempt to constrain his powers, even temporarily.

Key words: Presidential Decisionmaking, Trump, steroids, covid-19, 25th Amendment

$\mathrm{T}$ here are many aspects of President Donald Trump's recent diagnosis of COVID-19 that are concerning to all students of presidential decision-making, especially those interested in the Twenty-Fifth Amendment and the serious structural limitations on its ability to remove an impaired president from office. While most of the discussion around Trump's illness has focused on his symptoms, his treatments also raise serious questions for students of biopolitics broadly construed. Two of the medications that the president reportedly received, remdesivir and the monoclonal antibodies produced by Regeneron, are sufficiently new that clear and common side effects have yet to be documented and established. However, the steroid that Trump has reportedly been taking, dexamethasone, has a long history with well-established side effects, many of them psychoactive in nature.

The use of steroids in Trump's case appears inherently contradictory. In clinical trials, dexamethasone has only been indicated for use in serious cases of COVID-19, precisely because it can result in a worse outcome in mild cases by suppressing the body's innate immune system (NIH, 2020). When the illness produces a cytokine storm, where the immune system overreacts, steroids can prove lifesaving. But in more mild cases, the suppression of immune function is counterproductive. In Trump's case, the public was told both that his case was mild and that he was put on a treatment reserved only for those with the most serious hospitalized cases.

Several aspects of this contradiction are problematic. First, it suggests that the president was not given the

doi: $10.1017 /$ pls.2020.28

Correspondence: Rose McDermott, Department of Political Science, Brown University, Providence, RI, USA. Email: rose_mcdermott@brown.edu correct treatment. Perhaps he insisted that everything possible be thrown at his condition. If the doctors acceded to this request, this reflects the standard VIP problem, whereby prominent people receive less than optimal treatment, either because their desire for secrecy prevents the inclusion of appropriate providers or, as is more likely in the president's case, because the patient directs the treatment without adequate medical knowledge of how best to treat the illness at hand (Post \& Robins, 1993). As the old saying goes, Trump being his own doctor may mean he had a fool for a patient, but it also highlights the central problem raised by the power imbalance between patient and doctor. Trump's physician, Dr. Sean Conley, is a U.S. Navy doctor; this means he is under the president's chain of command. Given the president's history, Conley is no doubt well aware that the president could fire him, potentially threatening his retirement, if he was unhappy with his treatment or even with the presentation of his condition to the public. The desire to make the president happy was painfully clear in Conley's press conferences, when he put the best possible face on the president's condition and even acknowledged that he did so in part to ensure that the president was not upset with the presentation of his condition on television.

The second, even more serious concern results from the biological consequences of the steroids themselves. Trump is certainly not the first president to rely on steroids for their lifesaving properties. John F. Kennedy was heavily dependent on them throughout his presidency for treatment of his Addison's disease (McDermott, 2007). Yet steroids have clear and common side effects (Caplan et al., 2017). Long-term use presents one set of problems, most commonly including cataracts and bone degeneration. But even short-term use can result in a number of psychoactive consequences. 


\section{Rose McDermott}

These are not unlike the effects experienced when taking amphetamines. A recent "caution" on the use of dexamethasone succinctly notes,

Another established side effect of Dexamethasone is that it can cause steroid induced psychiatric reactions, including psychosis, mood changes, behavioural disturbance and cognitive dysfunction. These symptoms can develop within days of a $5 \mathrm{mg}$ single dose even in those who have no psychiatric history. The incidence of a psychiatric episode to steroids has been recorded at being between $13 \%$ and $62 \%$. Many of these are mild reactions such as euphoria and increased irritability and may not impact on functioning, but patients need to be warned about the severe reactions in up to $5-6 \%$ of patients, such as mania and suicidal thoughts. (Morganstein et al., 2020)

Note that the National Institutes of Health guidelines suggest 6 milligrams as the standard treatment for seriously ill COVID-19 patients. Other research indicating that the effects are even more common suggests that treatment with antipsychotics or mood stabilizers may be warranted during steroid treatment:

Psychiatric adverse effects during systemic corticosteroid therapy are common. Two large metaanalyses found that severe reactions occurred in nearly $6 \%$ of patients, and mild to moderate reactions occurred in about $28 \%$. Although disturbances of mood, cognition, sleep, and behavior as well as frank delirium or even psychosis are possible, the most common adverse effects of shortterm corticosteroid therapy are euphoria and hypomania....Dosage is directly related to the incidence of adverse effects but is not related to the timing, severity, or duration of these effects.... In severe cases or situations in which the dose cannot be reduced, antipsychotics or mood stabilizers may be required. (Warrington \& Bostwick, 2006)

The president's erratic behavior, particularly his whipsaw transitions regarding a new COVID-19 relief package in Congress, and his desire to begin public appearances so shortly after his release from the hospital strongly suggest that some of these reactions may be exacerbated, if not generated, by steroids. Further, withdrawal from steroids is not a trivial undertaking; even with careful and gentle tapering, extreme fatigue, irritability, and depression typically result.
These side effects are particularly concerning not simply because the country is confronting a once-ina-century pandemic, a severe economic downturn, and critical issues of racial injustice, all requiring immediate, sustained, and attentive leadership. They are even more worrisome given that Trump has access to the nuclear codes. This is certainly one of the reasons that no one person should have complete control of such destructive weapons, as former defense secretary Bill Perry and others have recently argued (Perry \& Collina, 2020). However, it also raises critical issues regarding the inadequacy of the Twenty-Fifth Amendment in removing an impaired leader, temporarily or otherwise.

The third section of the Twenty-Fifth Amendment allows a president who recognizes his limitations to notify Congress and transfer power temporarily to the vice president. George W. Bush did this, for example, during the hours he was under anesthesia for a colonoscopy. This kind of temporary suspension is more likely in the case of a transient illness such as the president apparently experienced. If his illness, or the psychiatric consequences of his treatment, warranted his temporary removal from office, this section would cover that need, as long as the president agreed to such a suspension.

The fourth section of the amendment is reserved for removing a leader who is not able or willing to acknowledge his impairment. The problem is that such action requires a majority of either cabinet members or Congress to certify the impairment and agree to remove the president from office. The person charged with assuming presidential duties under such a circumstance, the vice president, typically does not want to look like he or she is trying to usurp power, and thus has always been reluctant to undertake such actions. In addition, other leaders tend to believe that their positions and power are contingent on the president staying in power, making the incentives to remove a seriously impaired leader almost disappear. Different proposals have been put forward by various commissions to address these concerns, but none has been implemented as yet, and none could be undertaken quickly. This leaves the country at the mercy of a leader whose decision-making ability may be even more seriously impaired than might normally be the case.

The current case of Trump's illness and treatment is an immediate example of the effect of illness and medication on decision-making. Indeed, the illness itself has been reported to cause enduring "brain fog" and other forms of encephalopathy in many patients, sometimes enduring for months. And sometimes patients are sufficiently impaired that they do not fully realize the extent of their

Politics And The Life SCIEnces • XXXX $202 \mathrm{I} \bullet$ 


\section{Trump's COVID-19 diagnosis and presidential illness}

disability while they are experiencing it. These facts all raise concerns in the case of a leader with the kind of power held by an American president. Trump's current illness and treatment should warn scholars and policymakers of the importance of developing better institutionalized protocols for handling leaders with documented illness and those under the influence of medication, particularly those with psychoactive effects. Without such protections, citizens risk being victimized by the consequences of severely impaired leadership.

\section{References}

Caplan, A., Fett, N., Rosenbach, M., Werth, V. P., \& Micheletti, R. G. (2017). Prevention and management of glucocorticoidinduced side effects: A comprehensive review: Ocular, cardiovascular, muscular, and psychiatric side effects and issues unique to pediatric patients. Journal of the American Academy of Dermatology, 76(2), 201-207.
McDermott, R. (2007). Presidential leadership, illness, and decision making. Cambridge University Press.

Morganstein, S. I., Morganstein, D. L., \& Morganstein, L. R. (2020). Dexamethasone caution. British Dental Journal, 229(7), 398-398.

National Institutes of Health (NIH). (2020, August 27). COVID-19 treatment guidelines. https://

www.covid19treatmentguidelines.nih.gov/immune-basedtherapy/immunomodulators/corticosteroids/

Perry, W. J., \& Collina, T. Z. (2020). The button: The new nuclear arms race and presidential power from Truman to Trump. BenBella Books.

Post, J. M., \& Robins, R. S. (1993). The captive king and his captive court: The psychopolitical dynamics of the disabled leader and his inner circle. Family Business Review, 6(2), 203-221.

Warrington, T. P., \& Bostwick, J. M. (2006). Psychiatric adverse effects of corticosteroids. Mayo Clinic Proceedings, 81(10), 1361-1367. 